\title{
Geopolítica de los monumentos: los próceres en los centenarios de Argentina, Chile y Perú (1910-1924)*/
}

\author{
The Geopolitics of Monuments: Sculptural Narratives \\ of the Founding Fathers at the Centennial Celebrations \\ of Argentina, Chile and Peru (1910-1924)
}

Pablo Ortemberg

CONICET-Universidad de Buenos Aires

Se analiza el lugar de las celebraciones de los centenarios patrios de Argentina, Chile y Perú a partir de sus proyectos escultóricos vinculados a la construcción de alianzas políticas. Los usos de los relatos sanmartinianos y bolivarianos desempeñarán un importante papel en la relación entre países que aún conservaban litigios fronterizos y territorios en disputa o que pretendían consolidarse como potencias mediadoras.

Palabras Claves: Centenarios; Geopolítica; Monumentos; Argentina; Chile; Perú.

This paper examines the role of the sculptures dedicated to the Independence Centennials in the making of the diplomatic relations between Argentina, Chile and Peru. The narratives centered in the Independence «heroes» José de San Martín and Simón Bolivar contributed to shape the relations among countries that were still disputing their borders and territory and competing for regional leverage.

Keywords: Centennial Celebrations; Geopolitics; Monuments; Argentina; Chile; Peru.

* Este trabajo contó con financiamiento de la beca de investigación del Centro de Estudios y Documentación Latinoamericana (CEDLA), Ámsterdam, Fundación Slicher Van Bath de Jong, y del proyecto PIP-CONICET 114-201101-00276. Una primera versión fue expuesta en el Seminario «Mobilités et circulation des pratiques et des savoirs dans l'espace atlantique, XIXe-XXe siècles», invitado por Pilar González Bernaldo en la Université Paris Diderot, el 15 de octubre de 2013. 


\section{Introducción}

En el arco conmemorativo de los centenarios de las independencias en Iberoamérica continental que se extiende de 1909 a 1930, los gobiernos apelaron al relato originario y a sus figuras heroicas consagradas tanto para fortalecer las identidades nacionales como para llevar a cabo políticas de acercamiento o distanciamiento con otros Estados. En este último sentido, operaron mediante una serie de lenguajes simbólicos que incluían invitaciones diplomáticas a ceremonias, agasajos, recepciones, envío de medallas y condecoraciones, incluso a través de marcas perennes en la materialidad de la ciudad, como el rebautizo de calles y plazas, y la edificación de monumentos. Estos recursos simbólicos fueron utilizados por los gobiernos para conseguir apoyo internacional en sus pujas limítrofes irresueltas o bien para consolidar su influencia en el tablero continental y hasta mundial. Aunque en alguna medida todos los países compartieron estas dos preocupaciones, en este trabajo consideraremos cuatro casos y nos centraremos en la gravitación internacional en torno a la escultórica de los próceres: los centenarios argentino y chileno de 1910 (conmemoración de la Revolución de Mayo y de la creación de la Primera Junta, respectivamente) a partir de las esculturas de Bernardo O’Higgins y José de San Martín; el centenario de la independencia del Perú en 1921, en el cual fue central el acto de inauguración de la estatua y plaza de San Martín en los albores de la autodefinida «Patria Nueva» promovida por el presidente Augusto B. Leguía; y, por último, los esfuerzos escultóricos del diplomático argentino Roberto Levillier — continuando los de Carlos Estrada - orientados para que su país no perdiera influencia geopolítica ante los Estados del Pacífico durante el auge bolivariano revitalizado durante el centenario de la batalla de Ayacucho en 1924.

La documentación consultada nos permitirá acercarnos al campo de las relaciones internacionales desde el prisma de los festejos centenarios entre Estados sudamericanos, antes que en el vínculo de cada uno de ellos con las potencias europeas y los Estados Unidos, cuestión más comúnmente problematizada (aunque no necesariamente desde la perspectiva de las fiestas patrias). A su vez, la casuística elegida está motivada, por un lado, por el carácter en buena medida compartido por los tres países del mito de origen nacional y sus protagonistas canónicos. Examinaremos, en este sentido, distintas apropiaciones nacionales de un pasado común en función de la política internacional del momento. 
Por un lado, Argentina y Chile firmaron los Pactos de Mayo en 1902, evitando una guerra inminente. Desde 1906 el gobierno de José Figueroa Alcorta intensificó la «política de acercamiento» entre los dos países y buscó realizarla plenamente durante los festejos de ambos centenarios en 1910. Eso favoreció en 1914 la formalización del Pacto ABC, oficialmente conocido como Tratado de No Agresión, Consulta y Arbitraje al que suscribieron al año siguiente Argentina, Brasil y Chile. Por otro lado, como es sabido, uno de los conflictos más prolongados y desgastantes en la región fue la llamada «cuestión del Pacífico»: la disputa entre Perú y Chile por la posesión de las provincias de Tacna y Arica, ocupadas por el país del sur luego de la guerra del guano y salitre (1879-1883) que también afectó a Bolivia. ${ }^{1}$ La época de los centenarios patrios en la región estuvo signada por esta amarga contienda que concluyó recién para aquellos dos Estados con el tratado de $1929 .{ }^{2}$ Si en 1908 ambos ya habían interrumpido sus relaciones a raíz del llamado «incidente de la corona», en 1910 y 1911 se dañaron gravemente a causa de la chilenización violenta de las provincias en disputa, quedando suspendidas hasta la firma del tratado. ${ }^{3}$

En el primer apartado argumentamos que los festejos y sus monumentos inspirados en la gesta independentista, en particular el impulso de edificación de la estatua de Bernardo O'Higgins en Buenos Aires y la estatuaria de San Martín, dieron la oportunidad a la Argentina de coronar la política de acercamiento con Chile y a la vez intentar consolidar su lugar de potencia en la región, y por ende en los altos tribunales de arbitraje, claramente en alianza y a la vez rivalidad con el Brasil, el otro poderoso. ${ }^{4}$ En cuanto al Perú, damos cuenta del modo en que intentó utilizar ese lenguaje simbólico en la cuestión de «las cautivas» y otros problemas limítrofes, inclinando la balanza diplomática a su favor mediante operaciones que radicalizarían su enemistad con Chile. Ambos países buscarán con sus festejos y sus monumentos la amistad de otros Estados.

Demostraremos, en los apartados segundo y tercero, que en 1921 la habilidad diplomática de Augusto B. Leguía pretendió debilitar la armonía

1 En 1883 se firma el Tratado de Ancón entre los dos países. Las provincias, antes de la invasión chilena pertenecientes al Perú, permanecerían bajo jurisdicción del país vencedor hasta que al cabo de diez años se efectuara un plebiscito para que sus habitantes decidieran su destino. El tratado fue reinterpretado constantemente, al tiempo que se avanzó en la chilenización de las cautivas.

2 Hasta el día de hoy subsisten desavenencias por la frontera marítima entre los dos, así como sigue en pie el reclamo boliviano por la salida al Pacífico.

3 González Miranda, 2004.

4 Este argumento, al que aquí incorporamos nuevo material documental, está desarrollado extensamente en Ortemberg, 2014a, 329-350. 
trasandina, o en todo caso procuró mejorar la predisposición del gobierno argentino con respecto a los intereses peruanos en torno de la figura de José de San Martín, intensificando el puente simbólico preexistente creado en torno a su figura entre sectores de la elite intelectual y sectores militares de ambos países. El centenario de Ayacucho, referido en el apartado cuarto, sin embargo, revitalizó una vieja corriente bolivariana en la cual Argentina tuvo que saber navegar para no quedar excluida de la fiesta americana y no ver menoscabado su lugar como potencia mediadora en la región, una preocupación que pareció más presente en los enviados diplomáticos argentinos en Lima que en el propio gobierno al que representan, el cual se manejó con prudencia para no alterar el acercamiento logrado con Chile y el frágil equilibro con Brasil.

Existen numerosos estudios sobre el valor pedagógico y nacionalizador «hacia adentro» de la sociedad estatal de los monumentos conmemorativos, su relación con los proyectos urbanísticos de la modernidad, o su rol en la dinámica museística y en la consolidación del campo artístico nacional. ${ }^{5}$ Otros autores han indagado en las representaciones del pasado y las políticas de memoria de la cual son portadores. Algunos comenzaron a utilizar fuentes documentales de archivos de cancillerías para develar las maniobras diplomáticas que pretendían interferir en la dinámica de los concursos en la medida que ponían en juego el prestigio nacional. ${ }^{6}$ En este trabajo cruzamos datos obtenidos en los archivos históricos de las cancillerías argentina, chilena y peruana, junto con fuentes periodísticas de estos tres países con el objetivo de examinar la función que han cumplido los monumentos en el tejido de alianzas internacionales en la región y, su contracara, en el afianzamiento de enemistades.

\section{San Martín y O'Higgins en la apoteosis de la amistad trasandina durante los centenarios del 10}

Los centenarios de la Revolución de Mayo y de la creación de la Primera Junta en Santiago de Chile, tal como argumentamos en otro

5 Gutiérrez Viñuales, 2004; Gorelik, 2010a y b; Malosetti Costa, 2010, LX, 1, 237, 439-471; Rentero, Watson, Di Meglio, 2010; Voionmaa Tanner, 2005; Majluf, 1994; Orrego Penagos, 2014, 327-342; Casalino Sen, 2006, X, 17, 285-309. Todavía son pocos los trabajos que comparen centenarios. Valiosas excepciones, dentro de un mismo país, Lempérière, 1995, XLV, 2, 317-352; o entre países, Fernández Bravo, 2006, 331-372; y más recientemente, Martinez, 2013, 10, 47-90. Un intento de comparación de los tres casos escogidos desde las historiografías, Alvarado Dodero, 2012.

6 Piccioni, 1997, 193-200. 
trabajo, constituyeron la apoteosis de la política de acercamiento entre los dos países, habilitada por los Pactos de Mayo de 1902 y especialmente impulsada desde 1906 por el presidente argentino José Figueroa Alcorta. Los festejos y ceremonias patrias de 1910 de ambos países fueron acciones políticas clave en la construcción de las relaciones bilaterales, las cuales dejarán su huella en los años siguientes tanto en el plano gubernamental como institucional y social. Para ello, fue central la labor de ambas cancillerías, en articulación con otras carteras ministeriales junto con una serie de instituciones intermedias, estatales y de la sociedad civil que incluían la comisión pro centenario chileno y argentino, federaciones estudiantiles y hasta la asociación de empleados de telégrafos o el gremio de tipógrafos, entre tantos ejemplos. Durante los centenarios se efectuaron las cumbres presidenciales con la visita de Pedro Montt a Buenos Aires durante los festejos de Mayo y la del saliente José Figueroa Alcorta a Santiago de Chile, para las celebraciones de septiembre. En la comitiva que acompañó a Montt podría verse casi un «mini Estado» en movimiento: primera dama, secretario, el ministro de Relaciones Exteriores de Chile Jorge Edwards, una comisión parlamentaria, más de 700 oficiales y cadetes del Colegio Militar con su propia banda de música, buques de guerra, oficiales del departamento de policía, varios periodistas y un grupo de señoras de la elite chilena. Buenos Aires lucía en calles y edificios públicos banderas chilenas y argentinas, los himnos de ambas naciones se entonaban tanto en actos oficiales como en forma espontánea por el público que paseaba por las calles.

Por su parte, el gobierno argentino y amplios sectores de la sociedad festejaron con exaltación los días patrios chilenos. Según el informe confidencial de Miguel Cruchaga Tocornal, ministro plenipotenciario chileno en Buenos Aires, el festejo «revistió, por el entusiasmo ferviente que se verificaba en el público, el carácter de una fiesta cívica Nacional», en la que se destacaron a lo largo de veinte cuadras las columnas de centros sociales, obreros y deportivos, junto con grupos de políticos y universitarios. La apoteosis de la fraternidad se completaba desde el punto de vista político con las cumbres presidenciales (a pesar de las muertes de Montt y Fernández), en conjunción con la euforia suscitada por la inauguración del ferrocarril trasandino a la par que se revitalizaban los acuerdos económicos para una cordillera libre. ${ }^{7}$

7 Lacoste, 2004, 37, I, 97-127. 
Era representativo de la tónica general estas palabras publicadas en un periódico de Punta Arenas:

¡Honremos la memoria de los próceres en este gran día del Centenario Argentino! Rivalidades sin objeto, inevitables pleitos de vecindad, distanciaron, hace diez años, a Chile y a la Argentina. Ni una sombra ha quedado de esos desvíos. ${ }^{8}$

Ahora estrechaban sus vínculos, en buena medida a partir de sus instituciones militares, en coherencia con una época de nacionalismos beligerantes. Mientras algunos articulistas chilenos expresaban sus quejas por el gasto y la supuesta contradicción al enviar Chile tantos soldados a un país con el que se quiere consolidar lazos de fraternidad, el coronel Cornelio Gutiérrez, director del Colegio Militar Argentino, escribió una carta a Cruchaga Tocornal, comunicándole su satisfacción por haber atendido al contingente de cadetes chilenos, huéspedes de tan intachable conducta, «durante su permanencia en esta Capital, que los ha considerado con razón como los niños mimados de sus días patrios» [resaltado nuestro]..${ }^{9}$ En contrapartida, un escuadrón del regimiento de granaderos a caballo general San Martín —recreado en 1903 y desde 1907 designado escolta presidencial- fue visitante ilustre en el centenario chileno. Llevaron consigo, a título de obsequio, una estatua en tamaño natural de un granadero, es decir, la representación de lo que era de por sí una recreación.

Los centenarios patrios sirvieron de vitrina del poderío naval y militar, fueron un importante ejercicio de ostentación que influía en el prestigio de los Estados. Varios comunicados confidenciales entre Cruchaga y el ministerio de Relaciones Exteriores en Santiago demuestran que se evaluaba seriamente en qué torneos participar con la tropa o cuántos buques enviar para que la nación conservara, ganara o, en todo caso, no perdiera su prestigio. En general, las comitivas extranjeras enviaban oficiales de alta graduación para las ceremonias, a veces vinculados también con la venta de armamentos y contratación de instructores militares. ${ }^{10}$ En todo caso, la omnipresencia del estamento militar en los homenajes de los centenarios trasandinos intensificó como nunca antes una tendencia sobre el monopolio

8 El Magallanes, Punta Arenas, 27 de mayo de 1910.

9 Archivo General Histórico del Ministerio de Relaciones Exteriores de Chile, Santiago de Chile (en adelante ACC), Argentina, vol. 209, 1909-1910, s/f, 1910, citado en Ortemberg, 2014a, 335.

10 El general Colmar von der Goltz representó a Alemania en el centenario argentino, mientras que el general Charles Mangin, héroe de Verdún, fue uno de los invitados ilustres en el centenario peruano en 1921. 
castrense de las conmemoraciones patrias. Un síntoma entre tantos fue la decisión del Comité Chile-Argentina en Santiago de que fueran los enviados militares chilenos los encargados de entregar la placa de bronce destinada a ser colocada el 27 de mayo en la importante ceremonia de inauguración del nuevo conjunto escultórico en honor a los ejércitos de la independencia realizado por el alemán Gustav Eberlein para la base de la estatua del general San Martín en Retiro. En este contexto, la revolución del 25 de Mayo de 1810 en Buenos Aires y la creación de la primera junta el 18 de septiembre del mismo año en Santiago de Chile ya se habían consolidado exitosamente en efemérides nacionales sustentadoras de un mito de origen centrado principalmente en la dimensión militar de los procesos independentistas, mito análogo a la corriente «libertadora del norte» en los que descollaban sus héroes a caballo: José de San Martín, Bernardo O’Higgins, Simón Bolívar, Antonio José de Sucre. Los actores políticos de otrora habían completado su transformación en símbolos estandarizados disponibles para un uso pedagógico nacionalizador. ${ }^{11}$ No obstante, durante los centenarios estos símbolos anclados principalmente en la materialidad plástica de los monumentos también funcionaron como dispositivos para construir alianzas políticas, sociales y de «hermandad» militar entre diferentes Estados nacionales.

El gobierno chileno agradeció al argentino en 1909 al enterarse de que la Comisión Nacional del Centenario había resuelto pedir la colaboración chilena en la convocatoria de un concurso exclusivamente entre artistas trasandinos destinado a construir una estatua del general brigadier Bernardo O'Higgins para erigirla en Buenos Aires. ${ }^{12} \mathrm{El}$ autor de la iniciativa había sido Norberto Quirno Costa, quien vislumbraba en esa estatua la «nueva enseña de la paz que por siempre nos vinculará con Chile» ${ }^{13}$. Marco Avellaneda, ministro del interior y presidente de la Comisión, escribía a Cruchaga: «pronto podremos entonces saludar en efigie al compañero ilustre del general San Martín con los mismos alborozos con que serán glorificados los héroes de esta república ${ }^{14}$. La decisión de incluir a O’Higgins en

11 Bertoni, 2007 [2001], 79-120.

12 Un examen de los debates que surgieron sobre el valor político de la obra artística y los obstáculos diversos que se presentaron para su elaboración, en Ortemberg, 2014a, 337-340.

13 Archivo Histórico de Cancillería, Ministerio de Relaciones Exteriores y Culto de la República Argentina, Buenos Aires (en adelante ACA), Caja 1144, Centenario argentino, Chile, Comisión Nacional, Buenos Aires, 19 de junio de 1909, en Ortemberg, 2014a, 340.

14 ACC, Argentina, vol. 206, 1909, Buenos Aires, 12 de julio de 1909, en Ortemberg, $2014 \mathrm{a}, 337$. 
el listado de próceres del centenario argentino cimentaba la política de acercamiento a la vez que se presentaba como acto de reciprocidad por la estatua de San Martín levantada años atrás en Santiago. «Ellos nos debían esa compensación y hoy satisfacen cumplidamente esa antigua y sagrada deuda», escribía en el periódico el historiador y parlamentario chileno Gonzalo Bulnes..$^{15}$ La construcción de la concordia del presente encontraba así su justificación metonímica en la evocación de la fraternidad de los dos héroes nacionales. Se incluyó en el programa de festejos de Mayo la colocación de la primera piedra por parte del presidente Montt. La estatua recién pudo inaugurarse en la Plaza Rodríguez Peña el 18 de septiembre de 1918, en el centenario de la batalla de Maipú.

Las procesiones cívico-militares a los pies de las estatuas se acrecentaron en la época de los centenarios. En torno al año 1910 se multiplicaron, por ejemplo, los bustos estandarizados de San Martín, en consonancia con la nueva «enseñanza patriótica» establecida desde 1908 por el Consejo Nacional de Educación ${ }^{16}$. Esto iba a la par con la instrumentalización internacional de los monumentos nacionales. En Buenos Aires, los jefes de las legaciones chilena y peruana solían enviar ofrendas florales cada 17 de agosto al mausoleo del prócer en la catedral y participaban asiduamente desde fines del siglo XIX, con homenajes a los pies de su estatua en Retiro, actos que más allá de las formalidades protocolares contenían un importante valor político para los actores del momento. Los protagonistas de la conmemoración no eran únicamente representantes diplomáticos u oficiales del ejército, del mismo modo que la política a través de las estatuas - y de su aparejada superposición de placas- tampoco tenía como escenario exclusivo la capital.

En numerosas ciudades y pueblos de la Argentina, como es sabido, proliferaron en 1910 aportes de muy diversos sectores de la sociedad para organizar suscripciones destinadas a erigir estatuas y diversos monumentos que expresaban el orgullo local (y sectorial) y su vínculo con el proyecto estatal. La participación de inmigrantes de los países vecinos fue significativa en muchos casos. En ocasiones, los monumentos levantados gracias al asociacionismo podían influir en la construcción o alteración de las relacio-

15 El Mercurio, Santiago, 5 de junio de 1910. También se oponía a la idea de que se levantara una estatua de Sarmiento en Santiago, pues, según él, el argentino había participado en la gestión del tratado secreto de 1873 .

16 Gorelik, 2010b, 208 y 210. Sobre el origen de los «batallones escolares» en relación a la consolidación del Estado desde finales de 1880, Bertoni, 2007. 
nes internacionales. Hemos dado cuenta en otro trabajo de un ejemplo de disputa entre la diplomacia peruana y chilena en Buenos Aires y en Francia ante la inauguración en 1909 de la estatua de San Martín en Boulogne-surMer, ${ }^{17}$ exponemos ahora tres ejemplos suscitados en territorio argentino pero fuera de Buenos Aires con el fin de reforzar este argumento y a la vez dar cuenta de las variantes locales. Primer ejemplo, el pueblo de San Martín, a una hora de distancia de la capital, programó la inauguración de una estatua del prócer el 24 de mayo de 1910. El comité organizador pidió a Cruchaga que gestionara la asistencia al acto de un congresal chileno para que hiciera uso de la palabra. Esto confirmaba tanto la importancia otorgada a la participación chilena en el centenario argentino, como la relevancia de las marcas escultóricas para vehiculizar la fraternidad bilateral. ${ }^{18}$

En la zona cordillerana, como segundo ejemplo, un ingeniero chileno residente en San Rafael, provincia de Mendoza, exigía al gobierno chileno, en nombre de su colectividad, el reemplazo inmediato del vice-cónsul por comportamiento «inmoral». Una vez terminado el baile que las autoridades argentinas obsequiaron el 18 de septiembre para homenajear al país hermano, el funcionario, junto con dos jóvenes y unas «niñas alegres», se dirigieron a las 2 de la madrugada hasta la plaza principal y colocaron a modo de broma una escupidera en la cabeza de la estatua del prócer. Los autores fueron detenidos por las autoridades locales. El ingeniero resaltaba la indignación compartida de chilenos y argentinos, y recordaba que la estatua había sido erigida gracias a la suscripción popular de argentinos, chilenos y otros extranjeros residentes, el 9 de julio del año anterior. ${ }^{19}$ Así, para evitar un conflicto diplomático, la cancillería de Santiago resolvió destituir sin miramientos al funcionario cuestionado. Como último ejemplo, en la ciudad de Mendoza, la importante colonia de chilenos solicitó ayuda financiera a su gobierno para obsequiar una placa con el escudo de Chile en los festejos de mayo. Exigían también que el Presidente Montt se detuviera en su paso a Buenos Aires para presidir la ceremonia, o en su defecto lo hiciera la Escuela Militar y las bandas del ejército asignadas a las celebraciones de Buenos Aires. ${ }^{20}$

17 Ortemberg, 2014a, 344. 1910.

18 ACC, Argentina, vol. 212, telegrama confidencial de Cruchaga a Cancillería, 9 de mayo de

19 ACC, Argentina, vol. 218, carta de Carlos Madariaga al ministro de Relaciones Exteriores en Santiago, 20 de septiembre de 1910.

20 ACC, Argentina, vol. 218, carta firmada por miembros de la colonia chilena en Mendoza dirigida al ministro de Relaciones Exteriores en Santiago, 19 de abril de 1910. 
Por su parte, el gobierno peruano no expresó sus condolencias al chileno ante la muerte de los dos presidentes, como tampoco se adhirió a sus festejos patrios de septiembre. El primer gobierno de Augusto B. Leguía envió al centenario de Mayo en Buenos Aires una embajada encabezada por el vicepresidente Eugenio Larrabure y Unanue, integrada también por Carlos Álvarez Calderón que a la sazón iba como nuevo ministro asignado a esa capital y delegado al congreso científico panamericano. Sin embargo, el informe confidencial que dirigió Álvarez Calderón al ministro de Relaciones Exteriores en Lima está teñido de sinsabores respecto a la participación peruana en la semana de festejos argentinos. Subraya el peruano la falta de previsión oficial durante el viaje en tren, junto con algunos desaires protocolares, en contraste con el tratamiento brindado a la embajada

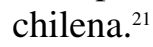

\section{San Martín como puente simbólico entre Argentina y Perú}

En vísperas de los centenarios de Chile y Argentina, Perú mantenía conflictos limítrofes con todos sus vecinos, aunque los más graves y duraderos fueron con Ecuador y Chile. ${ }^{22}$ La evocación peruana a sus dos Libertadores, San Martín y Bolívar, habilitó un lenguaje simbólico para intentar acercamientos políticos en el sur y norte del continente. De hecho, Chile temió al año siguiente de los festejos trasandinos que la celebración del centenario venezolano y el congreso bolivariano con sede en Caracas le diera la ocasión al Perú de sugerir una entente bolivariana que pudiera aislarlo.

Desde 1859, el Libertador de origen caraqueño tenía en Lima su estatua ecuestre en la plaza del Congreso, a tres cuadras de la Plaza Mayor. ${ }^{23}$ Se trataba del mismo sitio en el que el ministro Bernardo Monteagudo había ideado erigir en 1822 una columna trajana en honor al congreso,

21 Concluye en el informe: «debo sí advertir a V. S. que es marcado y aparente el esfuerzo que hace el elemento oficial argentino por hacer grata y agradable la estadía del Presidente y de las delegaciones de Chile», Archivo Histórico de la Cancillería, Ministerio de Relaciones Exteriores del Perú, Lima (en adelante ACP), 5-1-A, Argentina, caja 597, file 15, 232 fs, Informe confidencial del ministro Carlos Álvarez Calderón a ministro de Relaciones Exteriores en Lima, 27 de mayo de 1910, Buenos Aires, fs. 55-56.

22 Fernández Valdés, 2004; Tapia Figueroa, 2011, 156-173. En septiembre de 1909, Perú firmó tratados con Bolivia y Brasil.

23 Majluf, 1994. 
coronada por una estatua pedestre de San Martín, el otro Libertador del Perú. ${ }^{24}$ Gracias a la iniciativa de algunos jóvenes que integraban el «Comité Patriótico del Callao», los vecinos de ese pueblo efectuaron donaciones para construir en 1901 una estatua pedestre del Gran Capitán, la primera en concretarse en el Perú. Asimismo, gracias a la donación del coronel Pérez Roca, se colocó una pirámide con el ángel de la Gloria en su honor en la plaza de la Exposición. Desde mediados del siglo XIX, los gobiernos peruanos tenían la intención de construir la gran estatua del Protector y recién en 1904 se realizó un concurso bajo el mandato de José Pardo, pero su confección fue postergada una y otra vez. ${ }^{25}$ En todo caso, las figuras de ambos próceres gozaban de la simpatía nacional en amplios sectores de las elites y también del pueblo: constituían los rostros visibles de la historia patria, quedando asociado San Martín con la proclamación formal de la independencia que presidió en Lima el 28 de julio de 1821, y Bolívar vinculado a la gesta de Junín y Ayacucho. Esta última victoria, de repercusión continental, había sido obtenida el 9 de diciembre de 1824, como es sabido, bajo el comando del mariscal José Antonio Sucre.

Aunque oficialmente después de los Pactos de Mayo los gobiernos argentinos respetaron el acuerdo de no intromisión en la cuestión del Pacífico, y a pesar de lo observado en los centenarios de 1910, subsistieron siempre fuertes corrientes de simpatía entre sectores de la sociedad peruana y argentina. La figura de San Martín fue el vehículo simbólico primordial para mantenerla viva. Además de la gravitación de los no pocos residentes peruanos en Buenos Aires, Tucumán, La Plata y otras ciudades argentinas, la cuestión del Pacífico encontró en este país muchos defensores de la causa de esa nación, en especial entre intelectuales, universitarios vinculados al movimiento estudiantil de 1918, políticos y juristas, además de algunos militares: Alfredo Palacios, José León Suárez, el comandante Antonio Tassi, figuran entre los más constantes «amigos del Perú».

Los lazos eran fuertes, sobre todo en cultores de las historias patria y americana. Por ejemplo, Ricardo Palma, insigne escritor y director de la Biblioteca Nacional del Perú, mantuvo entre 1886 y 1912 una amistad epistolar con Adolfo Pedro Carranza, organizador del Museo Histórico Nacional. Carranza le pidió al primero iconografía sanmartiniana para

24 Ortemberg, 2012, 198. El congreso constituyente determinó en 1825 —después de Ayacucho- el cambio de Libertador.

25 Monteverde Sotil, 2010, 41-59. 
aumentar las colecciones del museo, mientras que Palma le comentaba en una misiva de 1900 su admiración por el Libertador, y a modo de anécdota, mencionaba el reclamo diplomático del ministro chileno que pesó sobre él en 1890 a raíz de unos versos anti-chilenos compuestos para la ceremonia de colocación de la primera piedra del monumento a San Martín. En otras cartas posteriores le envía postales con la fotografía del monumento erigido en el Callao. ${ }^{26}$ Así, San Martín fue el símbolo que permitió tejer un puente intelectual en el que cada país contribuyó en la gestión del pasado patrio del otro.

En la historia de la postergación de la estatua de San Martín en Lima pueden leerse los capítulos de las esperanzas y desilusiones de las carteras diplomáticas. En 1913, el gobierno argentino propuso enviar una embajada al Perú como «acto de reciprocidad» por la visita del vicepresidente peruano en los festejos de 1910, gesto formal, pues otras tantas irían a los demás países. Carlos Estrada, ministro argentino en Lima, se enteró de que en pocos meses se inauguraría en esta ciudad la estatua de San Martín, obra que se encontraba en España a cargo del escultor Mariano Benlliure. Creyó entonces conveniente a los intereses de la presencia continental argentina que la embajada planificara el viaje de modo que coincidiera con ese acto y además fuera con ella un escuadrón del regimiento de granaderos, quienes ya habían participado, como mencionamos anteriormente, en la inauguración de la estatua en Boulogne-sur-Mer y en los actos del centenario chileno. En la nota confidencial que dirigió al ministro de Relaciones Exteriores en Buenos Aires, sostenía que

conviene a todas luces imponer la personalidad del Gran Capitán de los Andes, sobre la figura de Bolívar, que tiene aquí, con gran sorpresa mía, tantos o más partidarios que San Martín. Por de pronto, su estatua ecuestre, uno de los más hermosos monumentos de esta ciudad, se ostenta dominadora. ${ }^{27}$

El ministro venía lidiando contra ataques reiterados a la figura de San Martín publicados en el periódico limeño La Prensa. En enero de 1914, celebró Estrada un cambio total en la opinión de este diario al ver acompañadas de un gran elogio al Libertador la publicación de las fotografías de la estatua de Benlliure. ${ }^{28}$ Estrada fue concibiendo el envío de la embajada

26 Las cartas fueron halladas y publicadas recientemente por Oguic, 2012.

27 ACA, caja 1147, Sección Protocolo, Perú, Nota confidencial del ministro Carlos Estrada al ministro de Relaciones Exteriores y Culto, Ernesto Bosch, en Buenos Aires, Lima, 22 de agosto de 1913. 28 Ibidem, 15 de enero de 1914. 
al acto de emplazamiento del monumento - iniciativa suya aprobada desde Buenos Aires desde el primer minuto- como un evento crucial para la política internacional Argentina. Llegó a solicitar permiso a cancillería para sugerirle al gobierno peruano que invitara al acto embajadas especiales, integradas por connotados representantes militares de países vinculados a la gesta sanmartiniana: Chile, Ecuador, Bolivia, Uruguay y Paraguay. Pero también embajadas de Colombia y Venezuela, pues desde allí «nació el torrente libertador del norte que vino a confundirse definitivamente con el del sur en esta ciudad de Lima». Según él, sería «la fiesta más grande de confraternidad americana que habría presenciado este continente». ${ }^{29}$ Brasil quedaba sugestivamente ausente en el programa soñado por el ministro. De todos modos, desde cancillería le ordenaron que dejara al Perú la decisión de convertir la ceremonia en evento americanista.

Podemos preguntarnos sobre el motivo por el cual Estrada daba tanta importancia a este acto ceremonial. En un pasaje de una de sus notas confidenciales nos da una clave:

jamás hasta la fecha se ha presentado a nuestro país, un momento más propicio, para exteriorizar su grandeza y poderío, y poner ambos al servicio de una amplia política de cordialidad americana, que sin obligarla con pactos peligrosos, ni con alianzas quijotescas, le atraiga, sin embargo, la simpatía de las repúblicas hispano-americanas de esta parte del continente. Conseguir esto, será conquistar la hegemonía moral... [resaltado nuestro]. ${ }^{30}$

Esto nos permite avanzar algunas reflexiones. La inauguración de monumentos en esta época se presentaba para muchos como una acción simbólica que admitía unir sin conflicto y de modo enmascarado los nobles valores americanistas con los propios intereses nacionales en su clave militarista. Permitía también librar batallas políticas mediante un lenguaje simbólico menos «peligroso» $\mathrm{o}$ «quijotesco» que las alianzas o pactos políticos explícitos. Por cierto, Argentina debía respetar su acuerdo con Chile respecto a su imparcialidad en el asunto pendiente con el Perú. Asimismo, la revitalización de la narrativa sanmartiniana le permitía a la Argentina no solo intentar imponer su gravitación ante el resto de los países bolivarianos, sino también excluir a su rival Brasil de la influencia continental. Recordemos que entre 1908 y 1914 se presenta un período álgido de competencia armamentista entre estos dos países, al que suele hacerse alusión como la «diplo-

29 Ibidem, 16 de enero de 1914.

30 Idem. 
macia de los dreadnought». ${ }^{31} \mathrm{Y}$ al mismo tiempo, bastante desconfianza suscitaba en el Perú el Pacto ABC formalizado en ese último año.

La estatua fue inaugurada finalmente en 1921 por el presidente A. B. Leguía, como acto central de los festejos del centenario. Un año antes se intensificaron en Buenos Aires las batallas simbólicas entre los gobiernos de Perú y Chile en torno a la figura de San Martín por el acercamiento al gobierno argentino que ello implicaba. El conflicto de 1909 evocado anteriormente con respecto a la inauguración del monumento de Boulogne-surMer parecía reproducirse el 17 de agosto de 1920, a los pies de la estatua de Retiro. El ministro peruano en Buenos Aires, Hernán Velarde, se empeñó en preparar a la opinión argentina para los festejos de su patria y a la vez en neutralizar los intentos chilenos de visibilidad pública a raíz de la conmemoración del centenario de la partida de la escuadra chilena desde Valparaíso. ${ }^{32}$ Además de la guerra publicitaria a través de la prensa (con periodistas pagos, desmentidas cotidianas o propagandistas espontáneos), intrigas y espionaje, a estas alturas podemos afirmar que las efemérides de la emancipación continental fueron concebidas por los diplomáticos como instancias cruciales para intervenir en el discurso público.

Velarde describe en nota confidencial dirigida al ministerio de Relaciones Exteriores en Lima detalles que según él no aparecen en la prensa o que se aluden minimizados, tal vez para «ocultar la desairosa situación de Chile y especialmente la del Ministro Chileno, cuya actuación en el homenaje se redujo a asistir en calidad de simple espectador». ${ }^{33}$ Resalta:

sin atribuir a las palabras que pronuncié a los pies de la estatua del Libertador otro mérito que el de la oportunidad, el hecho es que los aplausos me acompañaron desde que comencé a hablar prolongándose y convirtiéndose en una ovación al Perú cuando hube terminado. ${ }^{34}$

Comenta la nula recepción que tuvo, en cambio, la intervención de un fraile chileno, que para conseguir un mínimo aplauso fue pasando improvisadamente del «Viva Chile», al «Viva Chile y la República Argentina»,

31 Escudé y Cisneros, 2000, t. VII, cap. 37.

32 ACP, Argentina, 5-1-A, entrada, caja 743, file 3, 141 fs. Nota confidencial de Hernán Velarde al ministro de Relaciones Exteriores del Perú Meliton Porras, Buenos Aires, 26 de agosto de 1920, 73-78.

33 Ibidem, 74

34 Idem. 
hasta resignarse a un «Viva el Perú». ${ }^{35}$ Más allá de las posibles exageraciones del ministro peruano, al revisar la correspondencia diplomática de aquellos años, es notable la atención que los funcionarios peruanos en Argentina dedicaban tanto al tratamiento que la prensa local hacía de su disputa con Chile como a las performances públicas en ocasiones como esta.

Con todo, las esperanzas peruanas de que el gobierno argentino respaldara internacionalmente sus reclamos para anular el pacto de Ancón y se resolvieran de una vez por todas las cuestiones de Tacna y Arica, sufrieron un duro golpe a finales de este año 1920, cuando el doctor Pueyrredón, representante argentino en la Liga de las Naciones, se pronunció en contra de la revisión de pactos constituidos previamente a la constitución de la Liga $^{36}$ El presidente Leguía - había asumido su segundo mandato en 1919-, lejos de atizar las tensiones que ello generó en la opinión pública, redobló la apuesta ritual de acercamiento. No claudicó en sus intentos de aprovechar las oportunidades ceremoniales para ratificar, y en lo posible aumentar, la cordialidad con la Argentina que le brindó la conmemoración del centenario de la independencia en 1921.

En efecto, el presidente peruano se propuso invertir ingentes recursos del Estado en los festejos patrios por el centenario, dándole una impronta personalista al evento pero también anidando el objetivo de orientar esta acción simbólica en la obtención de un máximo de rédito político en las relaciones exteriores. ${ }^{37}$ Entre sus promesas de candidato estaba la de dar solución definitiva a los conflictos limítrofes subsistentes. Por lo tanto, no se trataba únicamente de enseñar los progresos del Perú al mundo civilizado sino de lograr también el apoyo «moral» de las naciones en sus temas fronterizos pendientes y en especial con el problema que acarreaba con Chile y Ecuador, los excluidos de la fiesta. El acto principal del centenario, como dijimos, fue la inauguración de la plaza y estatua de San Martín en el centro de la capital el día 27 de julio. De las 34 legaciones y embajadas especiales que asistieron, además de la de Estados Unidos y la de la madre

35 «Subió a las gradas de la estatua un fraile dominico que llevaba al pecho una cucarda con los colores de Chile [...] dio lectura a una breve alocución desaliñada y bombástica destinada más a glorificar a Chile que a San Martín y a servir de pretexto a un formidable "Viva Chile" que lanzó con toda la fuerza de sus pulmones, pero que repercutió en el vacío», Ibidem, 74.

36 El presidente Yrigoyen lo explica en una entrevista realizada por el peruano José Carlos Bernales. La nota apareció con diferentes variantes el mismo día en los periódicos locales, La Prensa, El Comercio y El Tiempo, Lima, 30 de diciembre de 1920.

37 Basadre, 2005, t. 14, cap. 5. 
patria, fue la de Argentina, cuna de San Martín, una de las más destacadas y más agasajadas por el conjunto de la sociedad peruana. ${ }^{38}$

\section{La estatua y el tango de los granaderos en el centenario peruano}

Para congraciarse con la Iglesia, el presidente Yrigoyen nombró jefe de la embajada a monseñor Luis Duprat, gesto que no dejó de ser criticado por algunos sectores, como quedaba reflejado en un editorial del diario argentino La Nación al considerar que se rebajaba la importancia de la misión y resultaba extraño en una república laica. ${ }^{39}$ Sin embargo, la investidura eclesiástica fue aprovechada tanto por el mismo Duprat como por Leguía para imprimirle un aura de unión sagrada a la amistad con Argentina y de autenticidad «extra-política» al encuentro de dos pueblos. ${ }^{40}$ En efecto, el balance de la actuación de la embajada es sumamente positivo, de acuerdo con la cobertura de la prensa peruana, las reacciones de la sociedad local y los discursos que circularon.

La popularidad de la embajada se debió especialmente a la presencia de un escuadrón de granaderos del regimiento general San Martín que el gobierno argentino decidió enviar —inspirado en los viajes de 1909 a Francia, y 1910 a Chile - en el transporte Guardia Nacional, con sus caballos, en una travesía llena de peripecias. ${ }^{41} \mathrm{Si}$ los centenarios patrios, en general, fueron momentos para escenificar los progresos materiales, artísticos y sociales de las naciones - se estructuraron como exposiciones universales-, la prioridad argentina en este caso fue mostrarse desde la «cruz y la espada». La narrativa independentista comulgaba una vez más con los valores nacionalistas armamentistas de entonces. El envío de los granaderos, sin embargo, respondía a una tendencia militarista que se había consolidado como modelo de participación en los centenarios de la región, tal como menciona en una carta dirigida a Velarde el ministro de Guerra peruano. ${ }^{42}$

38 «Entre las embajadas [...] tal vez sea la argentina la que más recuerdos cariñosos lleve de su estancia entre nosotros, pues han sido muchas y muy afectuosas las demostraciones que en homenaje a la patria de San Martín, se han realizado en Lima y otras provincias...», Variedades, Lima, 3 de septiembre de 1921.

39 La Nación, Buenos Aires, 25 de mayo de 1921.

40 La Prensa, Lima, 14 de septiembre de 1921.

41 Gracias a testimonios diversos, el viaje ha sido reconstruido en Tamagno, 2003.

42 ACP, Argentina, 5-1-A, Salida, caja 786, file 14, 105, 17, Lima, 10 de enero de 1921. 
Por cierto, los granaderos no constituían un escuadrón más en representación protocolar del ejército argentino, sino que encarnaban el «regreso» al Perú del legendario cuerpo creado por San Martín. Su participación en las ceremonias fue central, en especial formando la guardia de honor en la inauguración de la estatua de su «padre». ${ }^{43}$ De modo semejante a lo sucedido durante la inauguración en 1905 de la estatua del coronel Francisco Bolognesi en Lima, cuando por deferencia el ejército peruano se puso al mando de Roque Sáenz Peña - compañero de armas del héroe de Arica e invitado de privilegio en la ceremonia-, esta vez se dio el comando de las tropas formadas al pie de la estatua del Libertador al general Carlos Martínez, agregado militar argentino. ${ }^{44}$ Mientras se entonaron los himnos de Perú y Argentina, se colocaron tres coronas en representación de las tres provincias cautivas (Tacna, Arica y Tarapacá). El desfile militar duró dos horas y participaron regimientos de Estados Unidos, Francia, Italia y España, así como el pueblo contempló también el vuelo de aeronaves peruanas, cuyos pilotos habían recibido entrenamiento en Argentina. ${ }^{45}$

Si bien la política de acercamiento con Argentina se sellaba principalmente en ceremonias de impronta militar, también intervenía la solemnidad religiosa: un grupo de damas limeñas bordó y obsequió al camarín de la Virgen de Luján una bandera peruana. Según un articulista, se trataba de

ofrendas a la Argentina, que estrecharán los vínculos de confraternidad con la República hermana necesarios hoy más que nunca ante los esfuerzos que hace Chile por enfriar el afecto que nos une por más de un siglo. ${ }^{46}$

Desde una dimensión social menos sacralizada fueron asimismo importantes las conferencias del comandante Tassi y del internacionalista José León Suárez, junto con la confraternidad por medio de un partido de futbol y un campeonato de tiro entre ambos países. El lenguaje festivo tradicional fue utilizado por originarios de Tacna, Arica y Tarapacá para montar un carro alegórico ostentando en un enorme lienzo representando la república Argentina. ${ }^{47}$

43 La popularidad de los granaderos llegó entonces a tal punto que los diplomáticos brasileños en Buenos Aires exigieron al gobierno argentino que enviaran al regimiento a sus fiestas por el centenario al año siguiente.

44 Se saludaron en la ceremonia el mariscal Cáceres y el general francés Mangin. Este último tuvo el honor de comandar al ejército peruano durante la gran parada militar en el Hipódromo.

45 Tamagno, 2003, 45.

46 El Tiempo, Lima, 14 de febrero de 1921.

47 Mundial, Lima, 12 de agosto de 1921. 
La inauguración simultánea de la estatua y de la plaza homónima - cuya ornamentación y jardines fueron obra de Manuel Piqueras Cotolí, con un entorno que ya ostentaba dos edificios art nouveau y se proyectaban otros - fue la postal de modernidad que enseñó el régimen al mundo. ${ }^{48}$ A pocas cuadras quedaba la tradicional Plaza de Armas y también la plaza de la Constitución con la estatua de Bolívar. En las revistas Variedades y Mundial las dos estatuas suelen ser soporte de crítica y comentarios sobre la coyuntura. En ocasiones la caricatura las hace dialogar amistosamente y comentan desde su caballo la situación del país. El bolivarismo no se vio opacado sin embargo en el programa de festejos sanmartinianos. Se inauguró el Museo Bolivariano y, en otra fase del programa, Germán Leguía y Martínez, primer ministro y ministro de Gobierno y Policía, pronunció un resonante discurso en honor a Bolívar a los pies de su estatua, rodeado de las comitivas extranjeras, escolares formados y grupos de boy scouts. ${ }^{49}$

Según el testimonio de las «modernas» revistas limeñas aludidas, los granaderos resultaron los divos de las fiestas del centenario peruano: la cámara los muestra junto al presidente Leguía, en camaradería con oficiales peruanos, los sigue en las recepciones dadas en su honor por diferentes corporaciones (incluidas las asociaciones obreras), los retrata visitando la ciudad de Huacho y el pueblo de Huaura — sitios de la gesta sanmartiniana-, asistiendo a la inauguración del monumento a Olaya, en Chorrillos, en fin, hasta hurga en su cotidianeidad en una nota de Mundial titulada «Cómo viven los granaderos»..$^{50}$ Además de ser revelador de un nuevo periodismo visual del «espectáculo» social, este tratamiento mediático nos permite detectar los clisés que la sociedad peruana albergaba sobre la identidad argentina y la imagen de nación que estos «embajadores» venían a representar. En la nota se los ve bailando el tango entre ellos (dos granaderos posan abrazados para la foto), ${ }^{51}$ se comentan los suspiros que arrebataban a las limeñas en los bailes, se elogia su habilidad como jinetes (el turf del «Centenario» y la imagen del militar a caballo coincidían en el Hipódromo) y se exalta la virilidad de su porte y uniformes. Su popularidad

48 Orrego Penagos, 2014; Casalino Sen, 2006. Otra estatua de San Martín se inauguró en Pisco, primera ciudad en la que estableció su cuartel general tras el desembarco.

49 Los discursos en honor a los Libertadores fueron impresos con intenciones de ser distribuidos en los colegios. Barros, 1921.

50 Mundial, 6 de agosto de 1921.

51 «Un tango que los oficiales bailan con la gracia de la chula más chula», Ibidem. En el centenario peruano también estuvo presente una orquesta típica con músicos argentinos. 
fue coronada cuando al final de la estadía regalaron la caballada al Perú. Con los caballos y lanzas obsequiados se crearía el regimiento histórico Húsares de Junín. De esta manera, un San Martín-símbolo se abría en una multiplicidad de representaciones que excedían la realidad del monumento de piedra e influía en la constitución de un imaginario peruano sobre la «argentinidad».

La hora de San Martín le permitió a Leguía publicitar la «Patria Nueva», apoyada en una reforma constitucional del año anterior que se presentó como como realización de la patria independiente proclamada por el Libertador. Recurría al mito de origen para inventar lo nuevo. ${ }^{52}$ Para vehiculizar sus objetivos en la política exterior, Leguía recreó la Orden del Sol sanmartiniana y obsequió condecoraciones, principalmente a los diplomáticos extranjeros que participaron en las fiestas patrias, en su afán de fortalecer el vínculo con el país invitado. También obsequió condecoraciones a argentinos que habían luchado del lado peruano en la guerra del Pacífico y envió una nueva placa al mausoleo de San Martín en la catedral de Buenos Aires. En sus mensajes al congreso resaltaba el éxito de las fiestas del centenario como un triunfo de su política exterior. La distribución de medallas de la Orden (mandadas a confeccionar a París) contribuyó a dar visibilidad y prestigio internacional al Perú en un momento crucial del conflicto con Chile. El canal formal de la diplomacia peruana apeló como nunca antes a la lógica del regalo como generador de obligaciones mutuas. Una buena parte de la opinión internacional en general se mostró en sus declaraciones por lo menos sensible a los reclamos peruanos ante Chile, al menos durante los agasajos y brindis del centenario.

Sin embargo, mientras los estudiantes argentinos se reunían a los pies de la estatua de San Martín en Retiro para enviar un mensaje de confraternidad a sus camaradas peruanos y chilenos, los universitarios en Lima experimentaban la progresiva intervención del nuevo régimen. Leguía, quien fuera al inicio agasajado con el título de «Maestro de la Juventud», comenzaba ahora a restringir libertades individuales y a adoptar medidas de persecución cada vez más duras contra las voces opositoras. Así, el doctor Víctor Andrés Belaúnde publicaba una carta de solidaridad con Luis Fernán Cisneros, director de La Prensa, periódico que será atacado y luego intervenido por el gobierno. En ella denunciaba:

52 Analogías entre San Martín y Leguía, por ejemplo, en panfletos como La revolución del 4 de julio de 1919..., 1920. 
me parece una amarga ironía que rindamos a los héroes el homenaje de las estatuas y los monumentos, manteniendo al mismo tiempo el ostracismo político, la cárcel por los delitos de opinión, desgarradas las inmunidades parlamentarias y despojado el Poder Judicial de toda autoridad y eficacia [...] Sí, Libertador, [...] al mismo tiempo que erigimos en tu nombre mármoles y bronces, la juventud te levanta hoy un monumento más grande: la decisión de luchar por la justicia, que es la garantía de la libertad y de la democracia. ${ }^{53}$

El boicot al centenario utilizaba el acontecimiento de la estatua para significar la protesta por la libertad. ${ }^{54}$

El centenario peruano tuvo gran impacto en el continente. En Argentina fue celebrado con entusiasmo, se lanzaron bombas y activaron sirenas en Buenos Aires al momento de la inauguración de la estatua de San Martín en Lima. Se colocó una placa de bronce con el nombre «Perú» a una calle céntrica, y en las ciudades de La Plata, Tucumán y San Juan hubo precesiones cívicas hasta los pies de sus respectivas estatuas del prócer (la revista limeña Variedades dedicó un artículo a la ceremonia de Tucumán). Una Comisión Nacional inmortalizó en un libro los agasajos argentinos al país hermano ${ }^{55}$ Velarde le comunicaba a su hermano por medio de un telegrama su entera satisfacción ante las muestras sinceras de adhesión del pueblo argentino a la fecha nacional. ${ }^{56}$ Por su parte, Chile no fue invitado y se mantuvo atento a cada gesto, símbolo y palabra pronunciada públicamente por los asistentes a la fiesta de su rival: asumió como cuestión de Estado los discursos pronunciados algunos invitados en medio de brindis y ceremonias.

El gobierno chileno consiguió que el Departamento de Estado norteamericano desautorizara unas declaraciones del embajador Alfred Douglas pronunciadas durante los agasajos en Lima en las que se colocaba a favor de la causa peruana en el litigio por las cautivas. ${ }^{57}$ Esto era sumamente delicado, porque Estados Unidos estaba mediando para la concreción del plebiscito tan postergado. Si bien el embajador boliviano Abel Iturralde Palacios no rectificó en sustancia declaraciones del mismo tenor, el gobierno de su país debió relativizar sus dichos con el fin de apaciguar la queja

53 La Prensa, Lima, 16 de marzo de 1921.

54 En el centenario argentino tampoco se cuestionó el lenguaje estatuario en sí. La oposición más radical al régimen proponía homenajeados alternativos. Gorelik, 2010b, 210.

55 Comisión Nacional de Homenaje al Perú, 1922.

56 ACP, Argentina, 5-1-A, Entrada, caja 766, file 8, 118, 99, telegrama de Hernán Velarde a su hermano Carlos Velarde, Buenos Aires, 30 de julio de 1921.

57 El Chileno, Santiago de Chile, 3 de agosto de 1921 
del gobierno chileno. ${ }^{58}$ Lucio Moreno Quintana, integrante de la embajada argentina, se batió a duelo con el periodista Moreno quien lo acusó de poner en peligro las relaciones entre Argentina y Chile con fervorosas declaraciones a favor del Perú en medio de los festejos limeños. ${ }^{59}$ De ese modo, el dispositivo simbólico del centenario favoreció la emisión de mensajes que alteraban el curso de la política internacional.

En general, la sociedad y prensa chilena oscilaron entre la «chilenización» del centenario peruano, reiterando tanto en notas periodísticas como en conferencias en cuarteles y colegios el protagonismo chileno en la independencia del Perú, ${ }^{60}$ y su negación, reduciendo los homenajes a su mínima expresión y hasta llegar a solaparlos con estentóreos festejos dedicados a su aliado Ecuador - el otro ausente de la fiesta peruana - por el 112 aniversario de su independencia ${ }^{61}$ En una entrevista otorgada en Lima, el periodista cubano Leopoldo Fernández Ross le decía a Luis Alberto Sánchez:

Chile debe de pensar en este momento cuán hondas consecuencias va a tener el centenario del Perú en el aspecto internacional [...] No se pueden figurar ustedes la importancia que adquiere el Perú con estas fiestas. ${ }^{62}$

Clemente Palma aseguraba en un editorial: «hoy Chile se siente aislado en el continente y en el mundo». ${ }^{63}$

Sin embargo, la confraternidad chileno-argentina lejos de resentirse se ratificaba con la adhesión del gobierno de Chile a la Comisión de homenaje por el Centenario de Guillermo Rawson, cuyo programa incluía la erección de una estatua en su honor. Según el jefe de la legación chilena en Buenos Aires, este prócer «impidió [...] que se aprobara un tratado, preparado en secreto, que habría roto la cordialidad [entre Argentina y Chile]». ${ }^{64}$ Por su parte, la prensa peruana no ocultaba suspicacias ante la cordialidad

58 Ibidem, 9 de agosto de 1921

59 La Prensa, Lima, 14 de septiembre de 1921. Alfredo Palacios fue padrino de L. M. Quintana en el duelo.

60 «Hoy se celebra un centenario glorioso para Chile», El Mercurio, Santiago, 28 de julio de 1921.

61 «Homenaje chileno al pueblo del Ecuador. Las fiestas realizadas ayer en Santiago y en las provincias. El brillante desfile del pueblo de la capital», El Mercurio, Santiago, 11 de agosto de 1921.

62 Mundial, 2 de agosto de 1921.

63 Variedades, 13 de agosto de 1921.

64 ACC, Fondo Argentina, Vol. 324, carta de Luis Izquierdo al Presidente de la Comisión Centenario de Rawson, Buenos Aires, 20 de junio de 1921. 
entre estos dos países. A comienzos de año, un corresponsal de El Comercio de Lima en Buenos Aires concluía que la «embajada chilena presidida por don Gonzalo Bulnes en Buenos Aires, con pretexto de inaugurar el monumento a O'Higgins, fue, en concreto, una misión encargada de atraer al presidente Irigoyen». ${ }^{65}$ Otro periódico advertía meses después sobre un posible viaje del presidente Arturo Alessandri a Buenos Aires y a Río de Janeiro para afianzar el pacto $\mathrm{ABC} .{ }^{66}$

\section{Los desafíos de Roberto Levillier en el centenario de Ayacucho}

Según Jorge Basadre, los festejos por el Centenario de Ayacucho fueron más imponentes que los de la independencia peruana. ${ }^{67}$ Esto era así no solo porque el Estado tenía más recursos para invertir, y muchas de las obras y monumentos proyectados en 1921 se concluirían recién en 1924, sino también porque se trataba al mismo tiempo de una fecha peruana y americana. Desde que asumió la jefatura de la legación argentina en Lima a comienzos de 1922, el historiador hispanista y americanista Roberto Levillier veló para que el bolivarismo imperante no eclipsara al símbolo San Martín y en consecuencia flaqueara el posicionamiento de Argentina en el tablero continental. Aunque movido por el mismo ideal que Carlos Estrada, dadas las circunstancias de la efemérides la tarea resultaba mucho más complicada. Recrudecieron en algunos periódicos peruanos las notas hiperbólicas sobre Bolívar y Sucre (durante los festejos se inauguró su estatua en Lima) y lógicamente menos enfáticas en relación a San Martín. Hasta hubo un debate entre parlamentarios peruanos porque algunos cuestionaban el rol histórico de este último. El director de El Comercio alzó la voz cuando al desplazar la columna en honor al Gran Capitán de la Plaza de la Exposición al municipio de Barranco, se le amputó el ángel de la Gloria con la idea de «reciclarlo», como ángel de la Victoria, en otro monumento que proyectaba la municipalidad por el aniversario de Ayacucho. ${ }^{68}$ Entre las obras por el nuevo centenario, se terminó de construir el majestuoso «Hotel Bolívar» de cara al monumento de San Martín de Benlliure.

65 El Comercio, Lima, 7 de enero de 1921.

66 El Tiempo, Lima, 15 de marzo de 1921.

67 Basadre, 2005, t. 14, cap. 5, 232.

68 «El mutilado monumento a San Martín», El Comercio, Lima, 16 de agosto de 1924. 
Levillier cuestionó en actos por el 25 de mayo la tendencia a hablar de «repúblicas bolivarianas», por su connotación separatista en contraposición al $\mathrm{ABC}$, y vigiló cada discurso de confraternidad «confederacionista» entre el Perú y los países bolivarianos pronunciados a los pies de las estatuas o en recepciones oficiales. ${ }^{69}$ Propuso que Argentina no solamente se adhiriera a las demás naciones americanas para la erección de un monumento en Ayacucho y enviara una embajada a los homenajes, sino que también obsequiara individualmente un monumento al Perú. El ministro argentino planteó una lucha en el plano conmemorativo contra el bolivarismo que excluía a Argentina, y al mismo tiempo contra las propuestas de Brasil que dejaban rezagado a su país. Las dilaciones para concretar el proyecto provinieron esta vez del congreso argentino debido a razones de presupuesto, desidia, solapada crítica al gobierno antidemocrático de Leguía e interés en no dañar el acercamiento logrado con Chile.

A finales de 1922, Levillier comenzó a enviar notas reservadas a cancillería en Buenos Aires sugiriendo que el país debía adherirse a los proyectos monumentales bolivarianos, los cuales, según él, se estaban concibiendo con exclusión de Argentina y, lógicamente, de Chile, apoyándose en una errónea lectura de la historia. Según el ministro, se concentraban injustamente en la batalla de Ayacucho ignorando la gesta sanmartiniana que había preparado el terreno para el desenlace..$^{70}$ Coincidiendo con su antecesor, estaba convencido de que

en los países del Pacífico, estos asuntos en otras partes, secundarios, son para nuestras relaciones, de una importancia primordial. Pesa sobre ellas en mal o buen sentido el recuerdo de la historia, más que cualquier otro factor económico, espiritual o político. Con países como Colombia, Ecuador, Venezuela a los que nos ligan escasos intercambios modernos, ¿qué vínculo fuerte y cordial nos queda salvo el pasado común? ${ }^{71}$

\section{Proponía obsequiar al Perú}

una estatua de «la Libertad» o de «la Victoria» para ser colocada, quizás como faro, en la entrada del puerto del Callao, por ejemplo en lo alto de la pequeña Isla de San Lorenzo! [De este modo] se evitarían personalismos, y la reiteración de estatuas existentes.

69 ACA, División Política, Perú, caja 2101, nota confidencial de Roberto Levillier al ministro de Relaciones Exteriores en Buenos Aires Ángel Gallardo, Lima, 6 de marzo de 1924.

70 Ibidem, 26 de diciembre de 1922.

71 Idem. 
Pero lo más interesante para nosotros es su concepción de las posibilidades y efectos del lenguaje simbólico:

la Argentina vendría así a ofrendar por segunda vez al Perú la victoria y la libertad. Y sería una manera discreta de recordarlo a perpetuidad, diciendo lo que había que decir, sin decirlo [resaltado nuestro]. ${ }^{72}$

Aunque Ángel Gallardo, ministro de Relaciones Exteriores en Buenos Aires, lo apoyaba en sus iniciativas, el congreso se demoraba en expedir la ley. En marzo de 1924, se lamentaba Levillier, «lo que siento es que el Brasil ha tomado la delantera, haciendo súbitamente suya una resolución del Congreso Americanista de Río del año 22». ${ }^{73}$ En aquella asamblea, Uruguay había propuesto que las naciones americanas sufragaran juntas un monumento para ser levantado en el lugar de la batalla de Ayacucho. La guerra por la hegemonía continental mediante la escultura conmemorativa no podía ser más intrigante, pues Levillier creía que el ministro de Brasil en el Perú «debió tener noticia aquí del proyecto argentino y exhumaron aquél para adelantarse al nuestro y si es posible, cruzarlo». ${ }^{74} \mathrm{El}$ peso de la historia, argumentaba el ministro, debía posicionar mejor a Argentina que a Brasil, pues el Imperio había dado refugio a los contrarrevolucionarios. Ante la falta de respuesta por parte del congreso y el progresivo desinterés de Ángel Gallardo, Levillier concluía con una advertencia: «no hay pequeños amigos, y puede que algún día, la amistad positiva del Perú, nos sea de gran alivio en momentos difíciles». ${ }^{75}$

Aunque había sido invitado a las fiestas de Ayacucho, el presidente Marcelo T. de Alvear se excusó de asistir por cuestiones de política interna. Manuel de Freyre y Santander, ministro peruano en ese momento en Buenos Aires, entendió que en efecto no era oportuno que el mandatario argentino dejara el ejecutivo al vicepresidente Elpidio González, un partidario de Yrigoyen. ${ }^{76}$ Tampoco fue designado el ministro Ángel Gallardo sino que se nombró a la cabeza de la embajada argentina a Agustín P. Justo, luciente ministro de Guerra, con el argumento de que la conmemoración refería a un hecho militar. ${ }^{77} \mathrm{El}$ único presidente que asistió a Lima para los

72 Idem.

73 Ibidem, 25 de marzo de 1924.

74 Idem.

75 Ibidem, 7 de julio de 1924.

76 ACP, Argentina, 5-1-A, caja 860, file 1, 1924, nota confidencial a Cancillería de Lima, Buenos Aires, 6 de mayo de 1924, 2.

77 Ibidem, 14 de agosto de 1924. 
festejos fue el de Bolivia, Bautista Saavedra Mallea, gesto que despertó sospechas en la prensa y diplomacia chilenas.

En todo caso, destacamos el contraste entre los esfuerzos de proyectos escultóricos conmemorativos vinculantes fomentados por los ministros argentinos afectados a Lima y el tibio interés por parte de la cancillería para acercarse más al gobierno peruano. En un descarnado informe, Freyre y Santander opinaba que «el argentino se considera europeo por civilización, y sud americano por un triste accidente geográfico». ${ }^{78}$ El mismo diplomático solicitará meses después al gobierno argentino apoyo manifiesto en caso de que los oficiales chilenos que acababan de destituir al presidente Arturo Alessandri interrumpieran las negociaciones por el plebiscito respecto de las provincias cautivas. En una entrevista con Ángel Gallardo evocaba

la amistad tradicional que une a los dos países [Perú y Argentina], amistad que debía en ciertas oportunidades, como esta, manifestarse por actos concretos y no limitarse a protestas platónicas sin valor efectivo. ${ }^{79}$

Gallardo eludió compromisos concretos con el Perú no sin insistir en esa amistad que se manifestaba en aquellas horas mediante el proyecto de regalo sugerido por Levillier. Los gobiernos argentinos de Yrigoyen y Alvear, en definitiva, no priorizaron la elaboración de alianzas bilaterales o pactos con el Perú, cuidando sensiblemente su vínculo con Chile y el frágil equilibro con Brasil. Uno de los argumentos discutidos en el parlamento argentino en contra de la iniciativa de Levillier apuntó al carácter antidemocrático del gobierno de Leguía. ${ }^{80} \mathrm{Si}$ la estatua de O’Higgins llegó a erigirse en el centro de Buenos Aires y la estatua de San Martín se impuso en el «nuevo centro» de Lima, la estatua-faro argentina de Levillier, ideada para iluminar uno de los más importantes puertos del Pacífico, nunca se construyó.

\section{Conclusiones}

La política de alianzas en un clima de nacionalismos armamentistas y de lucha por el predominio continental, en momentos de formación de tribunales para mediar la definición de conflictos limítrofes, encontró en la

78 Ibidem, 18 de junio de 1924, 52.

79 Ibidem, file 2, 9 de octubre de 1924, 21.

80 Levillier intentó en vano rebatirlo señalando que el regalo sería para el «pueblo» peruano y no para el gobierno de turno. ACA, Caja 2101, Exp. 14, Leg. 1, carta confidencial a ministro Ángel Gallardo, Lima, 26 de septiembre de 1924. 
arena simbólica de los monumentos conmemorativos y los festejos de los centenarios un lenguaje que no podía ser pasado fácilmente por alto. Los gobiernos seleccionaron próceres y acontecimientos a partir de las narrativas de las independencias no solo para fomentar mediante las estatuas el culto cívico integrador en el propio país, sino también para forjar alianzas internacionales. Por un lado, la estatua de O'Higgins corporizó la apoteosis del acercamiento entre Argentina y Chile que escenificaron los centenarios de 1910. Por otro lado, las estatuas de San Martín en Argentina, Chile, Perú - y hasta en Francia - fueron soporte de batallas entre estos dos últimos por la deferencia argentina, al tiempo que se enseñaban como símbolos de integración entre los «pueblos». El símbolo estatuario del prócer permitió articular a su vez las estrategias diplomáticas con la búsqueda de visibilidad, mediante el lenguaje "patriótico», del universo asociativo y corporativo, civil, militar y religioso en las tres naciones estudiadas.

El ministro Carlos Estrada pretendió aprovechar el inminente arribo de la estatua de San Martín a Lima para que Argentina enviara una embajada integrada por un escuadrón del regimiento de granaderos, de modo que «los cascos del caballo de guerra de San Martín se tornarán, por sus efectos morales, en algo así como las garras de nuestra influencia moral y política» ${ }^{81}$ El lenguaje de las estatuas permitía, según el ministro, conquistar influencia y sellar alianzas evitando los peligros del pasado con la firma pactos o ententes. Eran tiempos del ABC y Argentina debía mantener su compromiso con Chile de no intromisión en la cuestión del Pacífico. Al mismo tiempo, el recurso al monumento permitía transmitir un doble mensaje sin conflicto: el de la cordialidad americana y a la vez el de poderío nacional-militar. En particular, la narrativa sanmartiniana brindaba a la Argentina la ocasión de contrarrestar la gravitación de los países bolivarianos (sugirió Estrada convertir la fiesta por la estatua de San Martín en una fiesta americana) y al mismo tiempo excluir a Brasil, la potencia rival en la región. Roberto Levillier reemplazó a Estrada en esta cruzada y con lucidez propuso utilizar el lenguaje de los monumentos para «decir las cosas sin decirlas». Consideraba que el recurso estatuario era fundamental para acercar a la Argentina a los países del Pacífico, con quienes solo los unía la historia, en ausencia de relaciones comerciales y políticas. Sin embargo,

81 ACA, caja 1147, Sección Protocolo, Perú, Nota confidencial del ministro Carlos Estrada al ministro de Relaciones Exteriores y Culto, Ernesto Bosch, en Buenos Aires, Lima, 16 de agosto de 1914. 
la política internacional de Yrigoyen, y después de Alvear, no creyó oportuno dar prioridad a estas iniciativas de acercamiento con el Perú que a pesar de lo argumentado podían despertar igualmente suspicacias trasandinas. No obstante, a pesar de la propaganda antileguiísta de los exiliados peruanos en Argentina, las relaciones gubernamentales con el Perú se mantuvieron estables y los festejos limeños de 1921 y 1924 incrementaron una corriente de simpatía en sectores intelectuales y de la sociedad en su conjunto vehiculizada por el puente-símbolo «San Martín». Este símbolo se manifestaba no solo en monumentos, sino también en la escenificación de los granaderos y llegaba a intervenir en el imaginario sobre la «argentinidad» que se re-creaba en la sociedad peruana.

En estas páginas hemos examinado cómo el recurso estatuario de los próceres funcionó como instancia de legitimación en el espacio público de la política exterior ante el gobierno agasajado y como expresión de poderío y cordialidad. Además de constituir un recurso de pedagogía cívica dirigida a los propios gobernados y un lenguaje para lograr visibilidad de diferentes sectores de la sociedad civil en su creciente dinámica asociativa, los monumentos han contribuido no solo en la confirmación estética de los cambiantes equilibrios de fuerzas entre los países, sino que han participado creativamente en su sensible definición.

Recibido el 21 de enero de 2014 Aceptado el 22 de septiembre de 2014

\section{Bibliografía}

Alvarado Dodero, Fausto: «La historiografía y el centenario de la independencia de las repúblicas sanmartinianas (Perú, Chile y Argentina)», Summa Humanitatis. Revista electrónica interdisciplinaria del Departamento de Humanidades, PUCP, 4, 2, Lima, 2012, http://www.revistas.pucp.edu.pe/ index.php/summa_humanitatis/article/view/2298/2246 (última consulta el 19 de enero de 2014).

Basadre, Jorge: Historia de la República del Perú, Lima, El Comercio, reed. 2005, t. 14.

Bertoni, Lilia Ana: Patriotas, cosmopolitas y nacionalistas. La construcción de la nacionalidad argentina a fines del siglo XIX, Buenos Aires, FCE, 2007 [2001].

Casalino Sen, Carlota: «Centenario de la Independencia y próximo Bicentenario: diálogo entre los próceres de la Nación, la "Patria Nueva" y el proyecto de 
comunidad cívica en el Perú», Investigaciones sociales, X, 17, Lima, Universidad Mayor de San Marcos, 2006, 285-309.

Comisión Nacional de Homenaje al Perú: Memoria y relación de los festejos celebrados en la República Argentina con motivo del primer Centenario de la Independencia del Perú y de la inauguración de la estatua de San Martín en Lima, Buenos Aires, Establecimiento Gráfico Ferrari, 1922.

El centenario 1821-1921: discurso del Dr. Germán Leguía y Martínez y discurso del Dr. Oscar G. Barros, Lima, Tip. de T. Scheuch, 1921.

El Chileno, Santiago de Chile, 1921.

El Comercio, Lima, 1920, 1921, 1924,

El Magallanes, Punta Arenas, 1910.

El Mercurio, Santiago de Chile, 1910, 1921.

El Tiempo, Lima, 1920, 1921.

Escudé, Carlos y Cisneros, Andrés (dirs.): «La diplomacia de los acorazados, 1908-1914», Historia de las Relaciones Exteriores Argentinas, VII, 37, 2000. http://www.argentina-rree.com/7/7-053.htm (consultado el 2 de agosto de 2013).

Fernández Bravo, Álvaro: «Celebraciones centenarias: nacionalismo y cosmopolitismo en las conmemoraciones de la independencia. Buenos Aires, 1910-Río de Janeiro, 1922», en Andermann, Jens y González Stephan, Beatriz (eds.), Galerías del progreso: Museos, exposiciones y cultura visual en América latina, Rosario, Beatriz Viterbo, 2006, 331-372.

Fernández Valdés, Juan José: Chile y Perú: Historia de sus relaciones diplomáticas entre 1879 y 1929, Santiago de Chile, RIL eds., ADICA, 2004.

González Miranda, Sergio: El dios cautivo. Las Ligas Patrióticas en la chilenización compulsiva de Tarapacá (1910-1922), Santiago de Chile, LOM, 2004.

Gorelik, Adrián: «La memoria material: ciudad e historia», Boletín del Instituto de Historia Argentina y Americana «Dr. Emilio Ravignani», 33, serie 3, segundo semestre, 2010a, 181-187.

Gorelik, Adrián: La grilla y el parque. Espacio público y cultura urbana en Buenos Aires, 1887-1936, Bernal, Universidad Nacional de Quilmes, 2010b [1998].

Gutiérrez Viñuales, Rodrigo: Monumento conmemorativo y espacio público en Iberoamérica, Madrid, Cátedra, 2004.

Homenaje del Pueblo de Antofagasta a la República Argentina..., Antofagasta, Imp. Castro, 1910.

La Mañana, Santiago de Chile, 1910.

La Nación, Buenos Aires, 1921.

La Prensa, Lima, 1920, 1921.

La revolución del 4 de julio de 1919: homenaje del pueblo peruano al Sr. D. Augusto B. Leguía presidente de la república en el primer aniversario, Lima, Tip. Unión, 1920. 
GEOPOLÍTICA DE LOS MONUMENTOS: LOS PRÓCERES EN LOS CENTENARIOS

Lacoste, Pablo: «Vinos, carnes, ferrocarriles y el tratado de libre comercio entre Argentina y Chile (1905-1910)», Historia, 37, I, Santiago de Chile, 2004, 97-127.

Lempérière, Annick: «Los dos centenarios de la independencia mexicana (19101921): de la historia patria a la antropología cultural», Historia Mexicana, XLV, 2, México, 1995, 317-352.

Majluf, Natalia: Escultura y espacio público, Lima, 1850-1879, Lima, Instituto de Estudios Peruanos, Documento de trabajo 67, 1994.

Malosetti Costa, Laura: «Arte e Historia en los festejos del Centenario de la Revolución de Mayo en Buenos Aires», Historia Mexicana. Los Centenarios de Hispanoamérica: la historia como representación, LX, 1, 237, México, julio-septiembre 2010, 439-471.

Martinez, Françoise: «Monumentos de papel. Las obras conmemorativas publicadas en México y Bolivia en el primer centenario de su independencia», Revista Boliviana de Investigación-Bolivian research review, 10, La Paz, agosto 2013, 47-90.

Monteverde Sotil, Rodolfo: «Proyectos estatales para erigir un monumento público a José de San Martín (Lima 1822-1921)», Hacia el Bicentenario. Revista electrónica del Vicerrectorado de Investigación de la Universidad Nacional Mayor de San Marcos, 1, Lima, 2010, 49-51.

Mundial, Lima, 1921.

Muñoz, Miguel Ángel: «Un campo para el arte argentino. Modernidad artística y nacionalismo en torno al Centenario», en Wechsler, Diana (coord.), Desde la otra vereda. Momentos en el debate por un arte moderno en la Argentina (1880-1960), Buenos Aires, El Jilguero, 1998.

Oguic, Sofía: Correspondencia entre Ricardo Palma y Adolfo Pedro Carranza, Lima-Buenos Aires, Biblioteca Nacional del Perú-Embajada Peruana en Buenos Aires, 2012.

Orrego Penagos, Juan Luis: ;Y llegó el Centenario! Los festejos de 1921 y 1924 en la Lima de Augusto B. Leguía, Lima, Titanium, 2014.

Ortemberg, Pablo: «Los centenarios patrios en la construcción de alianzas y rivalidades internacionales: los festejos trasandinos de 1910, la estatua de O'Higgins y los bemoles peruanos», Jahrbuch für Geschichte Lateinamerikas/ Anuario de Historia de América Latina (JbLA), 51, Bölau (Viena, Colonia, Weimar), 2014a, 329-350.

Ortemberg, Pablo: Rituales el poder en Lima (1735-1828). De la monarquía a la república, Lima, Fondo Editorial Pontificia Universidad Católica del Perú, 2014 b.

Piccioni, Raúl: «Monumento al Centenario, un problema de Estado», VII Jornadas de Teoría e Historia de las Artes, CAIA, Buenos Aires, 1997, 193-200.

Rentero, Lucas; Watson, Ricardo; Di Meglio, Gabriel: Buenos Aires de fiesta. Luces y sombras del Centenario, Buenos Aires, Aguilar, 2010. 


\section{PABLO ORTEMBERG}

Tamagno, Mario Rodolfo: 100 años después. Los granaderos de San Martín regresan a Lima, Córdoba, Ed. del Copista, 2003.

Tapia Figueroa, Claudio: «Política exterior chilena en la disyuntiva regional: el conflicto ecuatoriano-peruano hacia 1910», Historia Crítica, 43, Bogotá, enero-abril 2011, 156-173.

Variedades, Lima, 1921.

Voionmaa Tanner, Liisa Flora: Escultura pública: del monumento conmemorativo a la escultura urbana. Santiago, 1792-2004, Santiago de Chile, Origo eds., 2005. 